\title{
Veri Zarflama Analizi ile Ülkelerin Medikal Turizm Etkinliğinin Ölçülmesi ${ }^{1}$
}

DOI: 10.26466/opus.572046

\section{Arzu Yiğit* - Vahit Yiğit**}

*Dr. Öğr. Üyesi, Süleyman Demirel Üniversitesi, İktisadi ve İdari Bilimler Fak.Isparta / Türkiye E-Posta: arzuyigit@sdu.edu.tr ORCID: 0000-0002-5777-3405

${ }^{* *}$ Doç. Dr., Süleyman Demirel Üniversitesi, İktisadi ve İdari Bilimler Fak.Isparta / Türkiye

E-Posta: vahityigit@sdu.edu.tr

ORCID: 0000-0002-9805-8504

*Arş. Gör., Süleyman Demirel Üniversitesi, İktisadi ve İdari Bilimler Fak.Isparta / Türkiye

E-Posta: $\underline{\text { selineroymak@sdu.edu.tr }}$

ORCID: $\underline{0000-0002-4377-9339}$

\section{Öz}

Bu çalışmanın amacı dünyadaki medikal turizm destinasyon alanlarına göre sinıflandırılan ülkelerin verimliliklerini veri zarflama analizi (VZA) tekniği kullanılarak tespit etmek ve Türkiye'de sağllk turizminin önemli bir bileşeni olan medikal turizm sektörünün dünyadaki medikal turizm destinasyon alanlarn içerisindeki konumunu belirlemektir. VZA analizinde CCR modeline göre ülkelerin medikal turizm etkinlikleri değerlendirilmiştir. VZA yönteminde değişkenler dört girdiden (GSMH'den sağlı̆̆a ayrılan pay, medikal turizm indeksi, hekim sayısı (bin kişiye)) ve iki çıktıdan (medikal turist sayısı, uluslararası turist sayısı içerisinde medikal turist oranı (\%)) oluşmaktadır. Yapılan analiz sonucunda araştırma kapsamındaki ülkelerin medikal turizm etkinliği ortalaması \%69.7 olarak tespit edilmiştir. Türkiye'nin verimlilik skoru ise \%28.97 olarak tespit edilmiştir. Dünyada ülkelerin önemli gelir kaynă̆g olan sektörlerden bir tanesi de turizmdir. Türkiye son yıllarda turizm sektöründe önemli gelişmeler sağlamıştır. Ancak Türkiye uluslararası turist sayısı içerisinde medikal turist oranının düşük olmasından dolayı medikal turizm pastasından oldukça düşük pay almaktadır. Türkiye'de medikal turizmin geliştirilmesi katkı sağlayacak sağlık politikaları uygulanarak ülke ekonomisine katkı yapması sağlanmalıdır.

Anahtar Kelimeler: Medikal turizm, Veri zarflama Analizi, Teknik verimlilik

\footnotetext{
${ }^{1}$ Bu çalışma 2-5 Mayıs tarihleri arasında Osmaniye'de gerçekleştirilen 18. Uluslararası İşetmecilik Kongresi'nde tam metin bildiri olarak sunulmuştur.
} 


\title{
Measurement of Medical Tourism Efficiency of Countries with Data Environmental Analysis
}

\begin{abstract}
The aim of this study is to determine the productivity of the countries which are classified according to the medical tourism destinations in the world by using data envelopment analysis (DEA) technique. In addition to determine the position in the medical tourism sector, medical tourism destination areas of the world, which is an important component of health tourism in Turkey. Medical tourism activities of countries were evaluated according to CCR model in DEA analysis. In the DEA method, variables consist of four inputs (from GNP to health, medical tourism index, number of physicians (thousand people) and two outputs (number of medical tourists, number of medical tourists in international tourists (\%). As a result of the analysis, it was found that the average medical tourism activity of the countries covered by the survey was $69.7 \%$. Turkey's efficiency score was determined as $28.97 \%$. Tourism is one of the major income sources of the countries in the world. Turkey has made substantial progress in recent years in the tourism industry. However, due to the low rate of medical tourists in the number of international tourists in Turkey is quite low share of medical tourism pie. The development of medical tourism in Turkey will increase its contribution to the national economy and health policies should be developed.
\end{abstract}

Keywords: $\quad$ Medical tourism, Data Envelopment Analysis, Technical Efficiency. 


\section{Giriş}

Tıp ve turizmin bir araya gelerek bütünleştiği bir alan olarak tanımlanan sağlık turizmi, ülkesinde sağlık ihtiyacını karşılayamayan hasta bireylerin tedavi olmak için farklı ülkelere gitmesini temel almaktadır. Sağlık turizmi teknolojinin ve tıbbın gelişmekte olan ülkelerde yeterince gelişmediği dönemlerde maddi durumu iyi olan bireylerin sağlık ihtiyaçlarını karşılamak için gelişmiş ülkelere gittiği bir durumken, son yıllarda gelişmekte olan ülkelerin tıp ve teknoloji alanında gelişmiş ülkeler ile rekabet edeceği seviyede kendini geliştirmesi ile yönünü bu ülkelere çevirmiştir (Barca, Akdeve ve Balay, 2013, s.103). Bu noktada sıklıkla sağlık turizmi kavramı ile karıştırılan medikal turizm kavramına kısaca değinilmesinde fayda görülmektedir.

Medikal turizm kavramı, temel olarak sağlık turizminin içerisinde ve onun bir alt dalı olarak değerlendirilmekle birlikte; sağlık turizminden daha sınırlı bir kavram olarak görülmektedir (Gökdayı ve Polat, 2015, s.910). Aynı zamanda sağlık turizminin bir bileşeni olarak da değerlendirilen medikal turizm kavramı (Tengilimoğlu, 2013, s.8) tedavi amaçlı sağlık turizmi olarak tanımlanmaktadır (İçöz, 2009, s.2259). Bu bakımdan medikal turizm kavramı, sağlık turizmi gibi sağlıkla ilgili her durumu kapsamaktan ziyade yalnızca tıbbi müdahalelerin gerekli olduğu durumlarda kullanılmaktadır (Connell, 2006, s.1094). Özellikle rutin sağlık kontrolleri, diş ve göz tedavileri, organ nakilleri ve kanser tedavisi gibi özellikli tıbbi müdahalelerin gerekli olduğu işlemler medikal turizm kapsamında değerlendirilmektedir (Aydın, 2012, s.93; Cohen, 2013, s.279; Connell, 2013, s. 2; Gümüş ve Özgüven, 2016, s. 6).

Giderek yaşlanan dünya nüfusuna bağlı olarak, hastalık yüklerindeki ve tedavi maliyetlerindeki artış başta gelişmiş ülkelerin vatandaşlarını olmak üzere, sosyal güvencelerini cepten karşılayan, tedavi giderlerinin bir kısmını ya da tamamını kendi ödeyen bireylerin de zor durumda kalmasına neden olmuştur (Tengilimoğlu, 2013, s. 8). Bu durum ise tedavi hizmetlerinin diğer ülkelere göre daha pahalı olduğu başta $A B D$ ve Avrupa ülkeleri olmak üzere gelişmiş ülkelerde yaşayan bireylerin sağlık ihtiyaçlarını karşılayabilmek için bu hizmetlerinin daha ucuz olduğu diğer ülkelere yönelmesine neden olmuştur (Gökdayı ve Polat, 2015, s. 9- 
10). Bununla birlikte alternatif ve yeni tedavi yöntemlerindeki gelişmelerin, uzun bekleme sürelerinin ve bireylerin daha kaliteli sağlık hizmeti alma isteğinin küresel çapta medikal turizmin hızla gelişmesindeki en önemli etkenler olduğu belirtilmiştir. Hızla gelişen bu küresel pazardan kendine pay almak isteyen ülkelerin ise medikal turizm alaninda en önemli aktör olmak için rekabet ettikleri ifade edilmiştir (Grail Research, 2009).

Nitekim 21. yüzyılın başlangıcında kendisini medikal turizm destinasyon alanı olarak tanıtan çok az sayıda ülke varken, son yıllarda yaşanan hızlı artış ile birlikte sektörün 100 milyar dolarlık bir paya ulaştığ 1 ve 6 milyondan fazla hastanenin bu küresel pazardan pay aldığ tahmin edilmektedir (Fetscherin ve Stephano, 2016, s.548). 2025 y1lında ise medikal turizm sektörünün 3 trilyon dolarlık bir sektör haline geleceği ifade edilmektedir. Ayrıca gelecek on yıl içerisinde dünya nüfusunun \%34'ünün medikal turizm amac ile farklı ülkelere seyahat edeceğinin öngörüldüğü bilinmektedir (www.medicaltourismindex.com). Hizla büyüyen sağlik turizmi ve medikal turizm sektöründe kendilerine yer bulmak isteyen ülkeler ve uluslararası kuruluşlar ilgilerini bu alana çevirmişlerdir. Bu bağlamda medikal turizm sektörü ile ilgili literatürde yer alan araştırmaların sayısında son yıllarda artış olduğu görülmektedir (Chee, 2007; Heung, Kucukusta ve Song., 2010; Yu ve Ko, 2012). Bu araştırmalar içerisinde pazar analiz araştırmalarının, verimlilik araştırmalarının (Turner, 2010; Rerkrujipimol ve Assenov, 2011) ve medikal turizm sektörünün teknik verimliliğinin değerlendirildiği çalışmalara (Debata, Patnaik, Mahapatra, ve Sreekumar 2013; Debata, Patnaik, Mahapatra ve Sreekumar, 2015; Karadayı ve Isık, 2018) olan ilgi artmaktadır.

Medikal turizm sektörünün temel odak noktası sektörde kalite standartlarını oluşturmak, iyi uygulamaları yaygınlaştırmak ve elde edilen gelirleri artırmaktır. Bu bağlamda, karar vericiler medikal turizm sektörünün teknik etkinliğinin belirlenmesinde aktif olarak yer almaktadır. Bununla birlikte sektörün karmaşık yapısı, çoklu girdi ve çıktı ilişkisine sahip olması nedeniyle performansını değerlendirmenin zor olduğu ifade edilmektedir. Bu sebeple medikal turizm sektörü için sağlık yöneticilerinin en önemli endişesinin sektörünün performansını değerlendirmek ve iyileştirme önlemlerine karar vermek için zayıf yönleri tespit etmek olduğu belirtilmektedir. Bu kapsamda Veri Zarflama Analizi'nin 
medikal turizm sektörünün performansını değerlendirmek için iyi bir performans değerlendirme aracı olduğu bildirilmektedir (Debata ve diğ. 2013, s. 25). VZA, kökeni Farrell'e dayanan ve sonrasında Charnes ve arkadaşları tarafından özgünleştirilerek geliştirilen parametrik olmayan bir verimlilik ölçümü yaklaşımdır (Karlaftis, 2004, s.357). VZA, benzer üretim yapan işletmelerin göreli verimliliğini ölçen doğrusal programlama tekniğinin kullanıldığ1 özel bir uygulama türüdür (Tetik, 2003, s.222). VZA, birden çok girdi ve çıtıya sahip birimlerin göreli etkinliğini ölçülmesini sağlayan bir yöntemdir.

\section{Gereç ve Yöntem}

Bu çalışmanın amacı dünyadaki medikal turizm destinasyon alanlarına göre sınıflandırılan ülkelerin verimliliklerini VZA tekniği kullanılarak tespit etmektir. Ayrıca Türkiye'de sağlık turizminin önemli bir bileşeni olan medikal turizm sektörünün dünyadaki medikal turizm destinasyon alanları içerisindeki konumunu belirlemektir. Çalışmada analiz yöntemi olarak VZA kullanılmıştır. Araştırmada ülkelerin verimlilik skorlarını girdi yönelimli CCR (Charnes-Cooper-Rhodes) modeli göre tespit edilmiştir. CCR modeli, toplam ağırlıklı çıktıların toplam ağırlıklı girdilere oranının maksimize edilmesini ve ölçeğe göre sabit bir getiri olduğunu yani girdilerdeki bir artışın çıktılarda orantılı bir artışa neden olacağı varsayımına dayanır.

Çalışmaya kapsamındaki ülkeler, 2018 yılında dünya genelinde ilk on sırada yer alan medikal turizm destinasyon alanları sınıflaması (Stephano, 2018) göz önüne alınarak seçilmiştir. Ayrıca çalışmaya dahil edilen ülkeler, Grail Research (2009) araştırma grubu tarafından yapılan medikal turizm destinasyon alanları sınıflaması göz önüne alınarak da 3 sınıfta kategorize edilmiştir. Maliyetin uygunluğu, sunulan bakımın kalitesi, tedavi için bekleme süreleri, yenilikçi/alternatif tedavi seçenekleri gibi kategoriler sınıflamada medikal turizmin çekici faktörleri olarak ele alınmaktadır. Bu faktörlerin düzeylerine, ülkelerin medikal yeterliliklerine ve yeteneklerine bağlı olarak medikal turizm destinasyon alanları; anahtar (önemli) bölgeler (1), yeni gelişen bölgeler (2) ve diğer bölgeler olmak üzere üç kategoriye ayrılmaktadır. Bu ülkelerden Meksika, Kosta Rika, Brezilya, Hindistan, Tayland, Singapur, Malezya ve Filipinler 1. bölgede; 
Birleşik Arap Emirlikleri, Güney Kore, Tayvan, Vietnam ve Şili 2. bölgede; Küba, Panama, Arjantin, Güney Afrika, Polonya, Macaristan, Ürdün, İsrail, Yeni Zelanda ve Türkiye 3. bölgede yer almaktadır. Analizde ülkelerin GSMH'den sağlığa ayırdıkları pay, medikal turizm indeksi, küresel barış indeksi ve 1000 kişi başına düşen hekim sayısı girdi değişkenleri olarak kabul edilmiştir. Medikal turist sayısı ve uluslararası turist sayısı içerisinde medikal turist oranı (\%) ise çıktı değişkenleri olarak alınmıştır (Tablo 1).

Tablo 1. Girdi ve Çıktı Değişkenleri

\begin{tabular}{cl}
\hline Değişken Türü & Değişkenler \\
\hline \multirow{3}{*}{ Girdi } & X1: GSMH'den Sağlığa Ayırdıkları Pay (\%) \\
& X2: Medikal Turizm Indeksi, \\
& X3: Hekim Sayısı (1000 Kişiye) \\
& Y1: Medikal Turist Sayısı \\
Çıktı & Y2: Uluslararası turist sayısı içerisinde medikal turist oranı (\%) \\
\hline
\end{tabular}

Medikal turizm indeksi (Medical Tourism Index-MTI), küresel bir ölçüm yöntemi olup sağlık turizmi bölgelerinin çekiciliğinin bölgesel tabanlı olarak değerlendiren bir performans ölçüsüdür (Medical Tourism Index, 2018). MTI, genel ülke ortamı içerisinde medikal turizm bölgesi olarak bölgenin çekiciliğini, sağlık hizmetlerinin maliyetleri, sağlık tesislerinin ve verilen tıbbi bakım hizmeti kalitesini genel ülke ortamı içerisinde değerlendirerek ölçmektedir (Fetscherin ve Stephano, 2016, s.540). MTI'nın, medikal turizm destinasyon alanları olarak ülkelerin cazibesini, medikal turizm bölgesi olarak değerlendirilmesini ve analiz edilmesini ayrıca nüfusun refahını artırmak için nasıl konumlandırılması gerektiğini dünya çapında ele alan bir referans noktası olduğu ve ülkelerin medikal turizm destinasyonları olarak performanslarını kıyaslamak için de paha biçilemez bir araştırma aracı olarak kabul edildiği belirtilmektedir (Medical Tourism Index, 2018). Çalışmada ülkelerin medikal turizm indeks değerleri Medical Tourism Index 2016 araştırmasından ve Fetscherin ve Stephano (2016)'nun çalışmalarından elde edilmiştir. Çalışmada diğer girdi değişkeni olarak alınan 1000 kişi başına düşen hekim sayısı ile çıktı değişkenli olarak alınan uluslararası turist sayısı içerisinde medikal turist oranı (\%) Dünya Bankası'nın veri tabanından elde edilmiştir (World Bank, 
2015a; World Bank, 2015b, World Bank, 2016). GSMH'den sağllğa ayrılan pay OECD veri tabanından elde edilmiştir. Medikal turist sayıları ise Statista (2015) ile Karadayı ve Isık'ın (2018) çalışmalarından alınmıştır.

\section{Bulgular}

$\mathrm{Bu}$ araştırmada dünyadaki medikal turizm destinasyon alanlarına göre sinıflandırılan ülkelerin verimliliklerini VZA tekniği kullanılarak tespit edilmiştir. Araştırmada verimlilik analizinde kullanılan girdi ve çıtı değişkenlerine ilişkin tanımlayıcı istatistikleri Tablo 2'de verilmiştir. Araştırmada; KVB olarak 10 ülkenin girdi ve çıktı değişkenlerine ilişkin merkezi dağılım ölçülerinden minimum, maksimum ortalama, standart sapma değerleri verilmiştir. Buna göre; ülkelerin girdi değişkeni olarak ortalama GSMH'den Sağllğa Ayrılan Pay \%5.6, medikal turizm indeksi 67.6, bin kişiye düşen hekim sayısı 1.48, medikal turist sayısı 510.913, uluslararası turist sayısı içerisinde medikal turist oranı (\%) 2.65 olarak tespit edilmiştir.

Tablo 2. Girdi ve Çıktı Değişkenlerinin Tanımlayıcı İstatistikleri

\begin{tabular}{lllll}
\hline & Min. & Max. & Ort. & SS \\
\hline $\begin{array}{l}\text { X1: GSMH'den Sağlı̆̆a Ayrılan } \\
\text { Pay (\%) }\end{array}$ & 3,77 & 8,91 & 5,696 & 1,955768 \\
X2: Medikal Turizm Indeksi & 60,6 & 73,56 & 67,645 & 4,747493 \\
X3: Hekim Sayısı (1000 Kişiye) & 0,4 & 2,1 & 1,48 & 0,597774 \\
Y1: Medikal Turist Sayısı & 50.000 & 1.200 .000 & $510.913,4$ & 376973,7 \\
$\begin{array}{l}\text { Y2: Uluslararası turist sayısı } \\
\text { içerisinde medikal turist oranı }\end{array}$ & 0,98 & 3,68 & 2,65 & 1,042971 \\
\begin{tabular}{l} 
(\%) \\
\hline
\end{tabular} & & & & \\
\hline
\end{tabular}

VZA sonucu hesaplanan teknik etkinlik skorları 0 ile 100 arasında olup bu değerlerin 100'e yaklaşması etkinliğin arttığını, sıfıra yaklaşması ise ülkelerin medikal turizm etkinliğin azaldığını göstermektedir. Tablo 3 ve 4'de ise ülkelerin CCR modeline göre teknik verimlilik bulguları verilmiştir. Ülkelerin ortalama verimlilik skoru 69.73 olarak tespit edilmiştir. CCR modeline göre en düşük değerin 28.97 ile Türkiye'ye ait olduğu saptanmiştır. 
Tablo 3. Ülkelerin CCR Modeli Teknik Verimlilik Sonuçlan

\begin{tabular}{ll}
\hline & CCR Modeli \\
\hline KVB Sayısı & 10 \\
Ortalama Verimlilik Skoru & 69,73 \\
En Düşük Hastane Verimlilik Skoru & 28,97 \\
Verimli Ülke Sayısı & 2 \\
Verimsiz Ülke Sayısı & 8 \\
Verimsiz Ülkelerin \%'si & $80.00 \%$ \\
Verimsiz Ülkelerin Ortalama Verimlilik Skoru & 62,17 \\
\hline
\end{tabular}

Tablo 4'te ülkelerin CCR modeli skorları verilmiştir. Yapılan teknik verimlilik analizde CCR modeline göre tam etkin olan ülkeler Tayland ve Singapur olarak tespit edilmiştir. Ülkelerin medikal turizm sektöründe etkin olup olmadıkları tespit edilmiş, etkin olmayan ülkelerin etkin olabilmeleri için hangi ülkeyi referans alması gerektiği belirlenmiştir.

\section{Tablo 4. Ülkelerin Medikal Turizm Verimlilik Sonuçları ve Referans Sıklığı}

\begin{tabular}{llll}
\hline Sıra No & KVB & Verimlilik Puanı & Referans S1klığ $\mathbf{1}$ \\
\hline 1 & Türkiye & $28,97 \%$ & $9(0,24) 10(0,02)$ \\
2 & Malezya & $98,36 \%$ & $9(0,55) 10(0,18)$ \\
3 & Güney Kore & $53,17 \%$ & $9(0,14) 10(0,38)$ \\
4 & Tayvan & $45,07 \%$ & $9(0,00) 10(0,40)$ \\
5 & Meksika & $91,43 \%$ & $9(0,83)$ \\
6 & Kosta Rika & $44,91 \%$ & $9(0,18) 10(0,20)$ \\
7 & Brezilya & $65,34 \%$ & $10(0,58)$ \\
8 & Hindistan & $70,07 \%$ & $9(0,57) 10(0,22)$ \\
9 & Tayland & $100,00 \%$ & \\
10 & Singapur & $100,00 \%$ & \\
\hline
\end{tabular}

Tablo 4'de görüldüğü üzere araştırmaya dahi edilen 10 ülkeden 5 'sı referans olarak hem Tayland hem de Singapur'u, Meksika Tayland'ı, Brezilya ve Tayvan'ın ise Singapur'u referans olarak alması gerekmektedir. Şekil 1'de de görüleceği üzere Malezya ve Meksika verimliğe çok yakın ülkeler olarak tespit edilmiştir. Verimliliği en düşük ülke ise Türkiye olup bunu Kosta Rika, Tayvan, Güney Kore, Brezilya ve Hindistan takip etmektedir. 


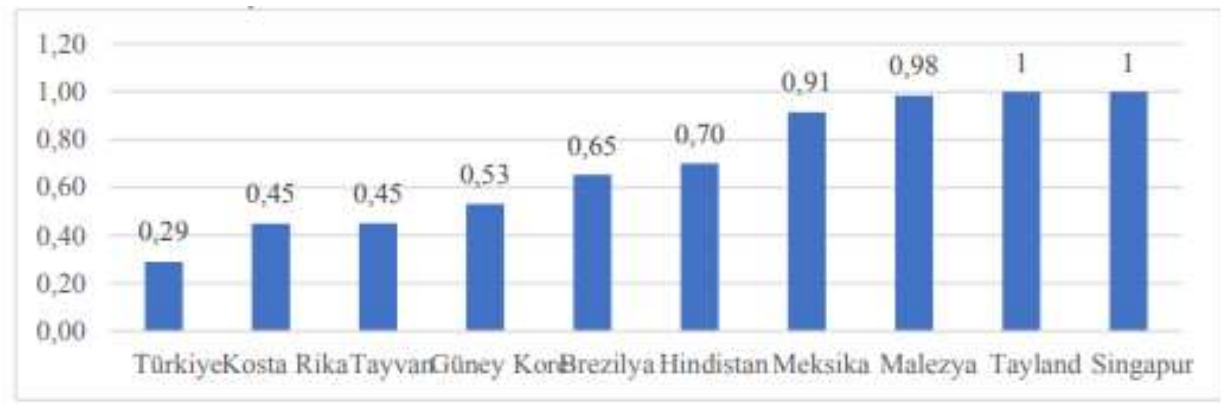

Şekil 1. Ülkelerin Medikal Turizm Verimlilik Sıralaması

\section{Tartışma}

Araştırma bulgularından elde edilen sonuçlar literatürde medikal turizm ile ilgili araştırma sonuçları ile tartışılmıştır. Literatürde ülkelerin küresel medikal turizm pazarında sahip oldukları pay (Horowitz, Rosensweig, and Jones, 2007, www.statista.com), bu pazarda kaçıncı sırada yer aldıkları (Stephano, 2018), hangi medikal turizm bölgesinde sinıflandırıldıkları (Grail Research, 2009), küresel medikal turizm pazarındaki durumları (Chakravarthy ve Deepthi, 2008; Gan ve Oviedo, 2013; Wong, Velasamy ve Arshad, 2014; Akbolat ve Deniz, 2017), medikal turizm amacı ile ülkelerin hangi nedenlerle tercih edildiği (Borg and Ljungbo, 2018; Collins, Medhekar, Wong ve Cobanoglu, 2019), ülkelerin medikal turizm alanında siralanması (Medical Tourism Index, 2018) ve medikal turizm verimliliklerinin yerel ölçekte (Debata ve diğ. 2013; Debata ve diğ. 2015; Kordić ve Šimundić, 2017) ve küresel ölçekte değerlendirildiği çalışmalar (Androutsou ve Metaxas, 2018; Karadayı ve Işık, 2018) yapılmıştır. Debata ve diğerleri (2013) tarafından Hindistan'da medikal turizm alanında hizmet sunan hastanelerin performansını kıyaslamak amacı ile VZA yöntemi kullanılarak yapılan çalışmada BCC modeline göre hastanelerin ortalama verimlilik skorunun 0.975 ; CCR modeline göre de 0,950 olduğu tespit edilmiştir. Çalışma sonucunda, verimsiz hastanelerin verimli hale gelebilmesi için referans alması gereken hastaneleri belirlenmiştir. 
Kordić ve Šimundić (2017) tarafından Croatian'daki 10 özel hastane ve 3 doğal spa merkezinin 2012 ve 2015 yılları arasında sağlık turizmi alanındaki teknik verimliliğini tespit etmek amacı ile VZA yöntemi kullanılmıştır. Çıktı yönelimli BCC modeline göre 2012 yılında 6 özel hastane ve 2 spa merkezinin verimli olduğu, 2015 yılında ise sayının düşerek 5 özel hastane ve 1 spa merkezinin verimli olduğu görülmüştür. 2012 yılında 0,910 olan ortalama verimlilik skorunun da 2015 yılında 0,820'ye düştüğü tespit edilmiştir.

Yine Debata ve diğ. (2015) tarafından Hindistan'daki 39 sağlık kurumunun medikal turizmin etkinliğinin tespit edilmesi için VZA yöntemi ile yapılan çalışmada hekim ve hemşire sayısı, ortalama tedavi maliyeti ve tedavi süresi, bekleme süresi, hemşire başına hasta sayısı girdi değişkenleri; yatak sayısı, hasta memnuniyet oranı, tedavi başarı oranı, hasta geri dönüş oranı, turizm acenteleri ile bağlantı sayısı, hastanenin şehir merkezine ve hava alanına uzaklığı çıktı değişkenleri olarak alınmıştır. Çalışma sonucunda BCC modeline göre 29 hastanenin; CCR modeline göre ise 27 hastanenin verimli olduğu tespit edilmiş ve verimsiz sağlık kurumlarının verimli hale gelebilmeleri için referans alması gereken sağlık kurumları belirlenmiştir. Ayrıca verimsiz olan ülkelerin hangi parametrelerde verimli ülkelerin gerisinde kaldığı (girdi değişkenlerinde ortalama tedavi süresi, çıktı değişkenlerinde memnuniyet oranı) tespit edilmiştir.

Karadayı ve Işık (2018) tarafından VZA yöntemi ile ülkelerin medikal turizm verimliliklerinin değerlendirildiği çalışmada ülkeler en iyi medikal turizm alanlarına göre kategorize edilmiş ve çalışma sonucunda Tayland ve Vietnam en verimli ülkeler olarak tespit edilmiştir. İsrail ve Kosta Rika en verimsiz ülke iken Türkiye de 0,17'lik verimlilik skoru ile verimsiz ülkeler kategorisinde yer almıştır. Androutsou ve Metaxas (2018) tarafından Avrupa Birliği'ne üye ülkelerin 2010-2014 yılları arasındaki sınır ötesi medikal turizm sektörünün verimliliği, VZA yöntemi ile değerlendirilmiştir. Yapılan VZA sonucunda üye ülkelerin sağlık sistemlerinin, o ülkenin vatandaşı olmayan hastaları tedavi etmede oldukça etkili olduğu ortaya konulmuştur. Ayrıca çalışma sonucunda dört yıllık süre boyunca medikal turizm alanında İrlanda ve Lüksemburg'un \%100 verimli olduğu; Macaristan, Çekya, Almanya ve Litvanya'nın ise en verimsiz ülke kategorisinde yer aldığı görülmüştür. Bu çalışmada ise Türkiye'nin de içinde bulunduğu ve 2018 yılı küresel medikal turizm 
sektöründe yer alan ilk 10 ülkenin medikal turizm verimlilikleri VZA yöntemi ile değerlendirilmiştir. Çalışmada GSMH'den sağlığa ayrılan pay (\%), Medikal Turizm İndeksi, 1000 kişiye düşen hekim sayısı girdi değişkeni olarak; medikal turist sayısı ve uluslararası turist sayısı içerisinde medikal turist oranı (\%) da çıktı değişkeni olarak alınmıştır. Çalışma sonucunda ülkelerin medikal turizm etkinlik ortalaması \%69.7 olarak tespit edilmiştir. Tayland ve Singapur tam verimli ülkeler; Türkiye ise \%28.97'lik verimlilik skoru ile en verimsiz ülke kategorisinde yer aldığ tespit edilmiştir. Karadayı ve Işık (2018) çalışmasında olduğu gibi bu çalışmada da medikal turizm verimlilik değerlendirilmesinde Türkiye'nin Tayland'ı referans alması gerektiği saptanmıştır.

Medikal turizm sektörü dünya genelinde pek çok ülkelerin söz sahibi olmaya çalıştığ 1 bir alan olmaya başlamıştır. Bu bağlamda ülkeler; kendi sağlık kurumlarının medikal turizm alanındaki etkinliğini, sundukları hizmetlerin kalitesini, verimliliğini ve medikal turizm sektöründe geri planda kaldıkları parametreleri tespit etmeye çalışmaktadır. Bununla birlikte medikal turizm sektörüne olan ilgi yalnızca ülkelerin kendi içinde yaptığı değerlendirmeleri içine alan kısacası yerel ölçekte değerlendirmeler yapan çalışmalar ile sınırlı kalmamakta, ülkelerin medikal turizm alanındaki yeterliliklerini çeşitli parametrelerle kıyaslayan, puanlayan ve ülkeler arası sıralamalar yapan çeşitli uluslar arası organizasyonlar tarafından da bilimsel raporlar yayımlanmakta ve literatürde de bu konuya olan ilgi hızla artmaktadır. Özellikle ülkelerin medikal turizm alanındaki teknik verimliliklerinin kıyaslandığı VZA çalışmaları bu bağlamda güncelliğini koruyan çalışmalar olmaktadır. Literatürde VZA yöntemi kullanılarak yapılan çalışmalar incelendiğinde yapılan ilk çalışmaların ülkelerin kendi medikal turizm verimliliklerinin değerlendirildiği kısacası ülkede yer alan sağlık kurumlarının verimliliklerini değerlendirdiği, sağlık kurumları arasında kıyaslamaların yapıldığı ve verimliliği düşük olan sağlık kurumlarına referans alması gereken sağlık kurumlarının önerildiği, sağlık kurumlarının hangi alanlarda eksikleri olduğu ile ilgili parametrelerin tespit edildiği çalışmalar olduğu görülmektedir. Daha sonları ise ülkeler arası verimlilik karşılaştırmaları yapılan, ülkenin medikal turizm sektöründeki konumunun belirlenmeye çalışıldığı ve medikal turizm alanında referans alması gereken ülkelerin önerildiği çalışmalar literatürde yer al- 
maya başlamıştır. Bu çalışmada da Türkiye'nin medikal turizm sektöründeki verimlilik durumu tespit edilmeye çalışılmış ve hangi alanlarda potansiyel iyileştirmeler yapması gerektiği ile ilgili önerilerde bulunulmuştur.

\section{Sonuç ve Öneriler}

Sağlık turizminin önemli bir dalı olan medikal turizm sektörüne olan ilgi dünya genelinde artmaktadır. Ülkeler medikal turizm pazarından kendilerine pay alabilmek için farklı stratejiler uygulamaktadır. Düşük fiyat politikası izleme, bekleme süreleri olmaksızın tedavi hizmeti sunma, yeni teknolojileri piyasaya sürerek sağlık turisti çekme, sağlık kurumlarını alternatif tedavi yöntemleri ile hastalıkları tedavi etme bu stratejilerden bazılarıdır. Ülkeler, uyguladıkları bu stratejilerle küresel medikal turizm pazarından daha fazla pay almaya çalışmaktadırlar. Araştırma sonucunda, araştırma kapsamındaki ülkelerin medikal turizm etkinliği ortalaması \%69.7 iken Türkiye'nin verimlilik skoru ise \%28.97 olarak en son sirada yer aldığı tespit edilmiştir. Medikal turizm verimlilik değerlendirilmesinde Türkiye'nin Tayland'ı referans alması gerektiği saptanmıştır. Dünyada ülkelerin önemli gelir kaynağı olan sektörlerden bir tanesi de turizmdir. Türkiye son yıllarda turizm sektöründe önemli gelişmeler sağlamıştır. Ancak Türkiye uluslararası turist sayısı içerisinde medikal turist oranının düşük olmasından dolayı medikal turizm pastasından oldukça düşük olarak yararlanmaktadır. Türkiye'de medikal turizmin geliştirilmesi ve ülke ekonomisine katkısını artıracak sağlık politikaları geliştirilmelidir Medikal turizm dünya çapında gelişmekte olan bir sektördür. Birçok ülkede medikal turizmin ulusal bir endüstri haline gelmiştir. Hindistan, Tayland, Singapur, Malezya gibi Asya ülkeleri popüler medikal turizm yerleri olmasına rağmen, Türkiye medikal turizmde istenilen seviyeye ulaşamamış ve medikal turizm pazarından yeterince pay alamamıştır (Yiğit, 2016). Dünyada önemli gelir kaynağı olan sektörlerden bir tanesi de turizmdir. Türkiye uluslararası turist sayısı içerisinde medikal turist oranının düşük olmasından dolayı medikal turizm pastasından düşük olarak yararlanmaktadır. Türkiye'de medikal turizm gelişmesini etkileyen faktörler küresel barış indeksinin düşük olması, sağlık kuruluşlarının alt yapısının yetersiz oluşu, tanıtım, işgücü eksikliği, 
dil ve iletişim, sağlık politikaları ve düzenlemeleri gibi faktörlerin etkilenebilmektedir. Türkiye medikal turizmde düşük maliyetle tedavi edilme ve bekleme süresinin kısa olması gibi avantajlara sahiptir. Ayrıca Türkiye coğrafi konum avantajını medikal ile birleştirerek daha fazla tercih edilen bir ülke olabilecek potansiyele sahiptir. Bu nedenle Türkiye'de medikal turizmin geliştirilmesi ve ülke ekonomisine katkısını artıracak ve urizm ile birleştirerek daha fazla tercih edilen bir ülke olabilecek potansiyele sahiptir. Bu nedenle Türkiye'de medikal turizmin geliştirilmesi ve ülke ekonomisine katkısını artıracak ve Türkiye'yi medikal turizm bölgeleri içinde cazibe merkezi haline getirecek sağllk politikaları geliştirilmelidir. Medikal turizm alanında yatırım yapacak yerli ve yabancı sermaye teşvik edilmesi gerekmektedir. Bu araştırma ülkelerin medikal turizm sektöründe performanslarını artırmaları konusunda yol gösterici olacaktır. Araştırmaya dâhil edilen ülkelerin medikal turizm kıyaslanması, referans almaları gereken ülkeler belirlenmiştir. Bu bağlamda araştırmanın sağlık plan ve politika belirleyicilerine, medikal turizm sektörüne bu alanda araştırma yapan akademisyenlere önemli katkı sağlayacağı düşünülmektedir. 
EXTENDED ABSTRACT

\title{
The Relationship between Secondary Schools Teachers' Critical Thinking Skills and School Health Perceptions
}

\author{
Arzu Yiğit - Vahit Yiğit - Selin Eroymak
}

Süleyman Demirel University

Health tourism, which is defined as an area where medicine and tourism come together, is based on the travel of patients who cannot meet their health needs to different countries for treatment. While health tourism is a state where technology and medicine have not developed sufficiently in developing countries, individuals with good financial status have gone to developed countries to meet their health needs, and in recent years, developing countries have turned their direction to these countries with the level of competing with the developed countries in medicine and technology. Although the concept of medical tourism is mainly considered within health tourism and its sub-branch; health tourism is seen as a more limited concept. The concept of medical tourism, which is also considered as a component of health tourism, is defined as therapeutic health tourism. Due to the aging population of the world, the increase in the burden of disease and treatment costs has led to the difficulties of individuals who meet their social security from their pocket and pay their own or all of their treatment expenses, especially the citizens of developed countries. This has led to the fact that the treatment services are more expensive than other countries, especially in the USA and European countries, and the individuals living in developed countries have turned to other countries where these services are cheaper in order to meet their health needs. However, the developments in alternative and new treatment methods, long waiting times and the desire of individuals to receive better quality health care services are stated to be the most important factors in the rapid development of medical tourism on a global scale. It is stated that countries that want to take their share from this rapidly developing global market 
compete to become the most important actor in the field of medical tourism.

The main focus of the medical tourism sector is to establish quality standards in the sector, to disseminate good practices and to increase revenues. In this context, decision-makers are actively involved in determining the technical effectiveness of the medical tourism sector. However, it is stated that it is difficult to evaluate the performance of the sector due to its complex structure, multiple input and output relationships. Therefore, it is stated that the most important concern of health managers for the medical tourism sector is to evaluate the performance of the sector and to identify weaknesses in order to decide on improvement measures. In this context, Data Envelopment Analysis is reported to be a good performance evaluation tool for evaluating the performance of the medical tourism sector DEA is a non-parametric productivity measurement approach, which is based on Farrell and then developed by Charnes et al. DEA is a special type of application that uses linear programming technique that measures the relative efficiency of similar manufacturing enterprises. DEA is a method of measuring the relative efficiency of units with multiple inputs and outputs.

The purpose of this study, the world medical tourism destination to the areas classified efficiency data envelopment analysis of countries by (DEA) to detect and medical tourism sector is an important component of health tourism in Turkey to determine its position in the global medical tourism destination areas. DEA analysis evaluated the countries' medical tourism activities according to CCR model. The CCR model aims to maximize the ratio of total weighted outputs to total weighted inputs. This model is based on the assumption that there is a constant return on the scale with the principle that an increase in inputs will result in a proportional increase in outputs. The countries included in the study were selected according to the classification of the top ten medical tourism destinations in the world in 2018. In addition, the countries included in the study were categorized into 3 classes considering the classification of medical tourism destination areas made by Grail Research (2009) research group. 
In DEA method, the variables consist of four inputs (share of health from GNP, medical tourism index, number of physicians (per thousand people)) and two outputs (number of medical tourists, proportion of medical tourists among international tourists (\%). MTI is a global measurement method that evaluates the attractiveness of health tourism regions on a regional basis, and as a medical tourism region within the general country environment, the attractiveness of the region, the costs of health services, the health care facilities and the quality of medical care services provided and evaluates. In this study, the medical tourism index values of the countries were obtained from the Medical Tourism Index 2016 research and from the studies of Fetscherin and Stephano (2016). In this study, the ratio of medical tourists (\%) among the number of physicians per 1000 people taken as the other input variable and the number of international tourists received as output variable was obtained from the World Bank's database. The share allocated to health from GNP is obtained from OECD database. The number of medical tourists is taken from the studies of Statista (2015) and Karadayı and Işık (2018).In the research, minimum, maximum average and standard deviation values were calculated from the central distribution measures of input and output variables of 10 countries as decision making units. According to this; as the input variable of the countries, the share of the average GDP allocated to Health is $5.6 \%$, the medical tourism index is 67.6 , the number of physicians per thousand is 1.48 , the number of medical tourists is 510.913 , and the proportion of medical tourists (\%) is 2.65 .

As a result of the analysis, the average medical tourism activity of the countries in the study was determined as $69.7 \%$. Turkey's efficiency score was determined as $28.97 \%$. Tourism is one of the sectors of the world's major source of income. Turkey has made substantial progress in recent years in the tourism industry. However, due to the low rate of medical tourists in the number of international tourists in Turkey is quite low share of medical tourism pie. To contribute to the development of medical tourism will contribute to health policy should be applied to the national economy in Turkey. 


\section{Kaynakça / References}

Akbolat, M. ve Deniz, N. G. (2017). Türkiye'de medikal turizmin gelişimi ve bazı ülkelerle karşılaştırılması. Uluslararası Global Turizm Araştırmaları Dergisi, 1(2), 123-139.

Androutsou, L. ve Metaxas, T. (2018). Measuring the effeciency of medical tourism industry in EU members states. MPRA Paper No. 92461.

Aydın, O. (2012). Türkiye'de alternatif bir turizm sağlık turizmi. KMÜ Sosyal ve Ekonomik Araştırmalar Dergisi, 14(23), 91-96.

Barca, M. Akdeve, E. ve Balay, İ. G. (2013). Türkiye sağlık turizm sektörünün analizi ve strateji önerileri. Isşletme Araştırmaları Dergisi, 5(3), 64-92.

Borg, E. A. ve Ljungbo, K. (2018). International market-oriented strategies for medical tourism destinations. International Journal of Market Research, 60(6), 621-634.

Chakravarthy, K. K. ve Deepthi, K. (2008). SWOT analysis on medical tourism. Indian Journal Research, 3, 299-301.

Chee, H. L. (2007). Medical tourism in Malaysia: international movement of healthcare consumers and the commodification of healthcare. Asia Research Institute Working Paper Series. No. 83.

Cohen, I. G. (2013). Transplant tourism: The ethics and regulation of international markets for organs. The Journal of Law, Medicine and Ethics, 41(1), 269-285.

Collins, A., Medhekar, A., Wong, H. Y. ve Cobanoglu, C. (2019). Factors influencing outbound medical travel from the USA. Tourism Review, 74(3), 463-479.

Connell, J. (2006). Medical tourism: Sea, sun, sand and surgery. Tourism Management, 27(6), 1093-1100.

Connell, J. (2013). Contemporary medical tourism: Conceptualisation, culture and commodification. Tourism Management, 34, 1-13.

Debata, B. R., Patnaik, B., Mahapatra, S. S. ve Sreekumar, S. (2013). Efficiency measurement amongst medical tourism service providers in India. International Journal for Responsible Tourism Perspectives on Health Tourism, Arte Publishing House, 2(1), 24-31. 
Debata, B. R., Patnaik, B., Mahapatra, S. S. ve Sreekumar. (2015). Efficiency measurement in medical tourism: a DEA approach. International Journal of Process Management and Benchmarking, 5(1), 90-112.

Fetscherin, M. ve Stephano, R.M. (2016). The medical tourism index: scale development and validation. Tourism Management, 52, 539-556.

Gan, L. L. ve Oviedo, N. (2013). Medical tourism: A SWOT analysis of Mexico and the Philippines. Available at SSRN 2234866.

Global Peace Index (2015). Measuring peace, its causes and its economic value, http://economicsandpeace.org/wp-content/uploads/2015/06/Global-Peace-Index-Report- 2015_0.pdf, 03.08.2018.

Gökdayı, İ. ve Polat, M. (2015). Isparta'da medikal turizmin yapılabilirliği üzerine bir çalışma. KMÜ Sosyal ve Ekonomik Araştırmalar Dergisi, 17 (29), 9-16.

Grail Research (2009). The rise of medical tourism summary. https://vdocuments.mx/rise- of-medical-tourism-summary.html, 03.08.2018.

Gümüş, M. ve Özgüven, E. (2015). Barış ve turizm ekseninde medikal turizm: çözüm süreci sonrası Batman hastanelerinde yabancı hasta akışı. Batman Üniversitesi Yaşam Bilimleri Dergisi, 5(2), 1-18.

Heung, V. C., Kucukusta, D. ve Song, H. (2010). A conceptual model of medical tourism: implications for future research. Journal of Travel and Tourism Marketing, 27(3), 236-251.

Horowitz, M. D., Rosensweig, J. A. ve Jones, C. A. (2007). Medicaltourism: globalization of the health care market place. Medscape General Medicine, 9(4), 33-38.

https://stats.oecd.org/ Health expenditure and financing, 20.03.2019.

https://www.statista.com/statistics/546678/top-global-destinations-bynumber-of-medical- tourists/, 21.04.2019.

İçöz, O. (2009). Sağlık turizmi kapsamında medikal (tıbbi) turizm ve Türkiye'nin olanakları. Journal of Yasar University, 4(14), 2257-2279.

Karadayı, M. A. ve Işık. M, (2018). A categorical dea framework for evaluating medical tourism efficiency of top destinations. I. Y. Topcu and C. Kahraman (Eds.), Operation Research Applications in (pp. 493-510). USA: Springer.

Karlaftis, M. J. (2004). A DEA approach for evaluating the efficiency and effectiveness of urban transit systems. European Journal of Operational Research, 152, 354-364. 
Kordić L. ve Šimundić, B. (2017), The efficiency of health tourism infrastructure in Croatia, The 11 th International Days of Statistics and Economics, Prague, September 14-16.

Medical Tourism Index, (2016). Homepage. https://www.medicaltourismindex.com/, 03.08.2018.

Medical Tourism Index, (2018). Background. https://www.medicaltourismindex.com/research-knowledge/background/, 05.08.2018.

Rerkrujipimol, J. and Assenov, I. (2011). Marketing strategies for promoting medical tourism in Thailand. Journal Tourism and Hospitality Culunary Arts, 3(2), 95-105.

Stephano, R. M. (2018). Top 10 medical tourism destinations in the world. Medical Tourism Magazine. Erişim Adresi, https://www.medicaltourismmag.com/article/top-10-medicaltourism-destinations-world. Erişim Tarihi, 03.01.2019.

Tengilimoğlu, D. (2013). Sağlık turizmi. Ankara: Siyasal Kitabevi.

Tetik, S. (2003). İşletme performansını belirlemede veri zarflama analizi. Yönetim ve Ekonomi: Celal Bayar Üniversitesi İktisadi ve İdari Bilimler Fakültesi Dergisi, 10(2), 221-229.

Turner, L. (2010). Medical tourism and the global market place in health services: US patients, international hospitals, and the search for affordable health care. International Journal of Health Services, 40(3), 443-467.

Wong, K. M., Velasamy, P. ve Arshad, T. N. T. (2014). Medical tourism destination SWOT analysis: A case study of Malaysia, Thailand, Singapore and India. In SHS Web of Conferences (Vol. 12, p. 01037). EDP Sciences.

World Bank, (2015a). https://data.worldbank.org/indicator/SH.MED.PHYS.ZS?end=2013\&amp;name_desc=true\&amp;start=20 $09,03.08$. 2018.

World Bank, (2015b). https://data.worldbank.org/indicator/SH.XPD.CHEX.GD.ZS?name_desc=true, 03.08.2018.

World Bank, (2016). https://data.worldbank.org/indicator/ST.INT.ARVL, 03.08.2018. 
www.medicaltourismindex, "Medical Tourism Industry Valued at \$100B Poised for 25\% Year-Over-Year Growth by 2025", https://www.medicaltourismindex.com/2016-medical- tourismindustry-valuation/, 02.08.2018.

Yiğit, V. (2016). Kamu hastanelerinde medikal turizminin gelişimini etkileyen faktörler. Süleyman Demirel Üniversitesi Vizyoner Dergisi, 7(15), 107-119.

Yu, J.Y. and Ko, T. G. (2012). A cross-cultural study of perceptions of medical tourism among Chinese, Japanese and Korean tourists in Korea. Tourism Management, 33(1), 80-88.

\section{Kaynakça Bilgisi / Citation Information}

Yiğit, A., Yiğit, V. ve Eroymak, S. (2019). Veri zarflama analizi ile ülkelerin medikal turizm etkinliğinin ölçülmesi. OPUS-Uluslararası Toplum Araştırmaları Dergisi, 12(18. UIKK Özel Sayıs1), 917-936 DOI: 10.26466-/opus.572046 